\title{
Knowledge, Attitudes and Practices of mothers on symptoms and signs of integrated management of Childhood Illnesses (IMCI) strategy at Buguruni Reproductive and Child Health clinics in Dar es Salaam
}

\author{
By Athumani Juma MD5 2007/08
}

\section{ABSTRACT \\ OBJECTIVE}

Assessment of mothers' knowledge, attitude and practices on symptoms and signs of $\mathrm{IMCl}$ strategy addressed illnesses July to September, 2007

\section{METHODOLOGY}

The cross sectional study was conducted among mothers with under five years old children receiving care at Buguruni Reproductive and Child Health Clinic, Dar-es-Salaam. Random sampling procedure was used to obtain 336 mothers.

Data collection from cooperative mothers was by the use of close ended swahili version of the questionnaire. Data was analysed using Epi-info statistical software. Confidentiality to any information disclosed by the mother was ensured.

\section{RESULTS}

Mothers recognized symptoms of childhood diseases as fever, cough, inability to play, irritability and restlessness and diarrhea by $92.5 \%, 85.3 \%, 83.5 \%, 81.1 \%$ and $80.8 \%$ respectively

Fatal symptoms of childhood diseases cited were convulsions, difficulty in breathing, unconsciousness, breastfeeding or eating difficulties and drowsiness by $92.5 \%, 90 \%, 89.8 \%, 88.0 \%$ and $88.0 \%$ respectively.

Most mothers (89.2\%) found no factor preventing them from seeking care, $98.2 \%$ and $99.4 \%$ of mothers took their children to health facilities once sick or developed any symptom of severe childhood disease.

\section{CONCLUSION}

Symptom recognition, attitude and practices were appropriate and directed towards proper management of childhood illnesses as addressed by the IMCl strategy. Therefore implementation of IMCl programmes in government health facilities has improved health seeking for childhood diseases.

\section{INTRODUCTION}

Every year 10.5 million children less than 5 years die in developing countries, mostly in sub-Saharan Africa. Although the annual number of deaths has been decreasing since 1970, reduction not evenly distributed, children in low- to middle-income countries are 10 times more likely to die before age 5 than children in the industrialized world ${ }^{1,2}$.

In 1998 more than 50 countries had IMR $\geq 100$ per 1000 live births. Seven in 10 of these deaths are due to Acute Respiratory Infection(ARI), Malaria, Malnutrition, Diarrhoea, Measles, Perinatal problems and often to a combination of these conditions $^{2}$. Every day millions of parents take children with potentially fatal illness to health facilities and in some countries three in four episodes of childhood illnesses are caused by one of these five conditions. Most sick children present with signs and symptoms related to more than one condition, this overlap means that a single diagnosis may not be possible or appropriate for treatment hence treatment may be complicated by the need of combination therapies for several conditions ${ }^{2}$.

Projections based on the 1996 analysis The Global Burden of Disease indicate that these conditions will continue to be major contributors to child deaths till the year 2020 unless significantly greater efforts are made to control them not forgetting the upcoming devastating effect of HIV/AIDS epidemic and tuberculosis ${ }^{2,3}$.

In response to this, World Health Organisation (WHO) and United Nations Children Funds (UNICEF) developed the $\mathrm{IMCl}$ strategy. At the core of this 
strategy is the integrated management of the most common childhood illnesses in developing countries through improving the case management skills of health staff, the health system itself as well as family and community practices ${ }^{4}$.

The $I \mathrm{MCl}$ has three components which are knowledge and skills of health care workers, health system support like health sector reform and improvements in family and community practices

The household (family) and community component of $\mathrm{IMCl}$ seeks to address household practices that are key for child survival, growth, and development. The 16 key practices identified and agreed upon by UNICEF/ Eastern and Southern African Region (ESAR), World Health Organization, Africa Regional Office (WHO/ AFRO) and partners can be categorized into four main areas: growth promotion and development, disease prevention, home management, and care seeking and compliance to treatment and advice.

This study has disclosed factors that decrease utilization of the health facilities in presence of signs and symptoms of $\mathrm{IMCl}$ strategy addressed illnesses as a proxy indicator of the factors that contribute to high mortality rate of under-fives due to major childhood diseases.

\section{METHODOLOGY}

A cross-sectional study was from July to September 2007 was conducted at Buguruni area in Dar es salaam city involving 336 reproductive and Child Health clinics attendees who brought their underfives on the basis of several health problems. Data were collected by the usage of a self-administered, closed ended Swahili version questionnaire. This data was then screened for errors and was coded before entering it into a statistical software. Epiinfo version 3.3.2. statistical computer program was used to analyse the data. Ethical clearance for the study was obtained from Muhimbili University of Health and Allied Sciences (MUHAS) Directorate of research and Publications via the office of the Dean, School of Medicine-MUHAS and confidentiality was guaranteed throughout the study period primarily by ensuring that only the principal investigator had the access to the respondents' answers. A verbal informed consent was sought before the interview process.

\section{RESULTS}

Refer Tables 1 and 2

\section{TABLE 1: MOTHERS' KNOWLEDGE ON SYMPTOMS OF IMCI-STRATEGY ADDRESSED ILLNESSES}

\begin{tabular}{|l|l|l|}
\hline \multicolumn{2}{|l|}{} & \\
\hline \multicolumn{2}{|l|}{} \\
\hline Coughing & 284 & 85.3 \\
\hline Fever & 308 & 92.5 \\
\hline Diarrhoea & 269 & 80.8 \\
\hline Inability to play & 278 & 83.5 \\
\hline Convulsions & 224 & 67.3 \\
\hline Breastfeeding inability & 261 & 78.4 \\
\hline Edema of both feet & 201 & 60.4 \\
\hline Weight loss & 228 & 68.5 \\
\hline Breathing difficulties & 249 & 74.8 \\
\hline Irritability and & & \\
restlessness & 270 & 81.1 \\
\hline \multicolumn{2}{|l}{} \\
\hline Difficulty in Breathing & 302 & 90.7 \\
\hline Breastfeed, Eating, \\
Talking difficulties
\end{tabular}

Percents totally exceed $100 \%$ because of multiple responses

${ }^{\mathrm{b}}$ Other mentioned fatal symptoms were severe diarrhea and vomiting everything and severe malnutrition

${ }^{1}$ Recognising any symptom of childhood disease was not associated with mothers' age, level of education or parity.

${ }^{2}$ Mentioning any fatal symptom of childhood disease was not associated with mothers' age, level of education or parity.

\section{DISCUSSION}

The study showed that knowledge on symptoms of childhood diseases was very high. All respondents were aware of at least one symptom of childhood diseases. Fever, cough, inability to play, irritability, restlessness, diarrhea, breastfeeding inability, breathing difficulties, convulsions, weight loss and edema of both feet were highly associated with 


\section{TABLE 2: Mothers' attitude toward IMCI symtoms}

\begin{tabular}{|l|c|c|}
\hline VARIABLE & $\begin{array}{l}\text { FREQUENCY } \\
\text { N=333 }\end{array}$ & PERCENT $^{\text {a }}$ \\
\hline $\begin{array}{l}\text { Perceived cause of } \\
\text { childhood diseases }\end{array}$ \\
\hline Bad weather & 299 & 89.80 \\
\hline Some organisms & 279 & 83.80 \\
\hline Witch craft & 126 & 37.80 \\
\hline Dirty environment & 303 & 91.00 \\
\hline Absence of water & 249 & 74.80 \\
\hline From God & 146 & 43.80 \\
\hline They just happen & 87 & 26.10 \\
\hline Other & 16 & 4.80 \\
\hline Don't know & 19 & 5.70 \\
\hline $\begin{array}{l}\text { Factor hindering } \\
\text { health care seeking } \\
\text { for under fives }\end{array}$ & \multicolumn{2}{|l}{} \\
\hline Lack of money & 20 & 6.00 \\
\hline Condition not serious & 7 & 2.10 \\
\hline Child not old enough & 4 & 1.20 \\
\hline Father does not agree & 3 & 0.90 \\
\hline Nothing & 297 & 89.20 \\
\hline Others & \multicolumn{1}{|l|}{} \\
\hline
\end{tabular}

a Percents totally exceed $100 \%$ because of multiple responses

b Other mentioned factors that can hinder seeking of care for the sick child was mother's illness

Perception on any cause of childhood disease was not associated with mothers' age, level of education or parity.

Mentioning no hindrance factor on seeking treatment of childhood disease was not associated with mothers' level of education, marital status, occupation or parity

childhood diseases. Fever and diarrhea recognition is nearly similar to the Tanzanian study ${ }^{9}$. This is because malaria is considered as a major problem in all Tanzania communities. The respondents in these two studies were living in holoendemic area of stable perennial malaria where people are aware of the clinical manifestation of the disease.

Concerning fatal symptom recognition almost all respondents (96.1\%) were aware of one or more fatal symptoms of childhood diseases. This awareness is much higher than the level noted in a study conducted in Bolivia 5 . Convulsions was the most responded fatal symptom of childhood disease (92.5\%) suggesting that this important symptom of complicated malaria is most recognized, as previously shown?. Breathing inability was the next most responded fatal symptom of childhood diseases being, followed by coma, breastfeeding or eating difficulties and lethargy (or drowsiness).

This can be explained by incorporation of $\mathrm{IMCl}$ strategy in the management of childhood diseases has improved mothers' symptom recognition than previously shown ${ }^{5,6}$. In a Pakistan study pneumonia recognition was almost universal and the main recognition and severity indicator was chest indrawing followed by signs and symptoms relating to the quality of breathing and the presence of high fever, anorexia and lethargy ${ }^{12}$ In Bolivia, 39\% of caregivers with fatally ill children recognized that their child was severely ill5.

In one Mexican study it was found that disease severity was not recognized in $40 \%{ }^{6}$. With respect to the cause of childhood diseases most respondents implicated dirty environment, bad weather, some organisms (germs) and absence of water however in few percentages some respondents still held the belief that God and witch craft were causes of childhood diseases. This awareness paralles previous studies ${ }^{11,12}$.

In Bangladesh respiratory illnesses were attributed to humoral imbalances, supernatural causes and 'negligent' mothers. Concept of germs was non existent ${ }^{11}$. In Pakistan, exposure to cold through a variety of mechanisms was perceived to be the dominant causal model of pneumonia and the concept of contagion was virtually non-existent ${ }^{12}$. This can be explained by differences in study settings as one study involved health volunteers ${ }^{11}$ and focus group discussion ${ }^{12}$. In this study bad weather, dirty environment and germs have come into minds of respondents probably due to increased emphasis on disease prevention as addressed by the community IMCI.

On seeking care most respondents cited no factor can hinder them from seeking care however lack of money and condition of the baby not being serious were cited less frequently. This is different from the previous studies which showed lack of money, distance to the facility and perception that illness is not serious were the main factors for children not to be taken to the health facility once they are ill in Mexico ${ }^{13,14}$.

This can be explained by provision of $\mid \mathrm{MCl}$ programmes free of charge to all children has increased health care seeking which was not the case in the previous studies ${ }^{13,14}$. Most mothers would send their children to the health facility however some would give home antipyretics and 
either send the child to the health facility or stay at home. Health care seeking is very high compared to previous studies ${ }^{14,9}$.

Also use of home antipyretics is lower than levels noted previously 9 . This can be explained by provision of $\mathrm{IMCl}$ programmes free of charge has increased accessibility to health care hence has decreased use of home treatment with antipyretics for underfives with fiver. Almost all mothers would seek health care when their under fives show any symptom of disease severity.

This is probably due to increased emphasis on symptom recognition of disease severity by $\mathrm{IMCl}$ programmes has improved caretaker skills to recognize danger signs in childhood diseases and free of charge of its services has enhanced health seeking behaviour which was not the case in Kenya ${ }^{6}$ and Mexico ${ }^{13,14}$.

Most mothers sought care from the government health facilities, dispensaries, pharmacies and private practitioners usage was low.

This is similar pattern to that in Zambia ${ }^{15}$ and in contrast with studies done in Kenya ${ }^{14,15}$.This is probably due provision of $\mathrm{IMCl}$ services free of charge has increased access to government health facilities and decreased accessibility private health providers which is associated with costs in their services as it is the case in Kenya.

Most mothers in the present study preferred to stop giving medication to their children before dose completion which is not the pattern in Kenya ${ }^{15}$ and Pakistan ${ }^{12}$. This can be due to incorrect messages being delivered to mothers on treatment of childhood diseases at health facilities with $\mathrm{IMCl}$ services has led to realistic expectation of cure hence has led to decreased change of physicians and treatment regimen which was the case in Kenya ${ }^{15}$ and in Pakistan ${ }^{12}$.

However some mothers were in agreement with stopping medication when the child gets better. This can lead to either under dosing if symptoms wane before the dose is completed as it was in Zambia $^{15}$ or overdosing if the symptoms persist even after the dose is completed.

Most of respondents agreed on giving medication for treatment and feeding their ill children at home while some would offer fluids and breastfeed their sick children.

This awareness on home management is appropriate and is in conformity with family and community practices that promote child survival and development stipulated by household and community component of $\mathrm{IMCl}^{16}$.

The practice of offering fluids and breastfeeding of sick children was low probably because ages of children were bimodal where by children of less than four months were on exclusive breast feeding while those who were older than four months are likely to be on complementary feeds ${ }^{17}$ however ages of children were not considered in this study.

Most respondents preferred to go back to the same health facility when their sick children develop complication. This is appropriate practice for management of childhood diseases and is probably due to application of $\mathrm{IMCl}$ programmes where by a mother is required to bring the child back to the health facility incase of complication which was not the case in a Mexican study ${ }^{13}$.

In this study no factor was found to be associated with mothers' knowledge on symptoms, attitudes and practices on childhood diseases. This is probably due to small sample size which was not the case in a Tanzanian study?.

\section{CONCLUSION}

In this study it was found that mothers were able to recognize symptoms of childhood diseases, also they had proper attitudes towards causes of childhood diseases and their practices were directed towards proper management of childhood illnesses as addressed by IMCI strategy. Therefore implementation of $\mathrm{IMCl}$ programmes in government health facilities has improved health seeking for childhood diseases.

\section{RECOMMENDATIONS}

These study findings have important policy implications hence they should be used to evaluate the success of implementation of $\mathrm{IMCl}$ strategy in the management of childhood diseases. Also $\mathrm{IMCl}$ programmes should be expanded and to be implemented in an all dispensaries and health centres including those in rural areas. 
Again association between either knowledge on symptoms, attitudes or practices on childhood diseases and socio-demographic factors were not obtained hence another study should be done in different settings in order to substantiate these findings.

\section{ACKNOWLEDGEMENT}

I would like to express my sincere gratitude to the sponsors of these elective study, the Ministry of Science and High Education (MSTHE) through Department of Community Medicine, School of Public Health and Social Sciences, Muhimbili University of Health Allied Sciences (MUHAS).

I am also gratefully acknowledge my supervisor Jane Mlimbila for her kindness and comments.

\section{REFERENCES}

1. World health report 1999

2. Murray CJ \& Lopez AD (1997) Mortality by cause for eight regions of the world: Global Burden of Disease Study. Lancet 349, 1269-1276.

3. Ahmad OB, Lopez AD \& Inoue M (2000). The decline in child mortality; a reappraisal. Bulletin of the World Health Organization 78, 1175-1191.

4. Gove S (1997) Integrated management of childhood illness by outpatient health workers: technical basis and overview. The WHO Working Group on Guidelines for the Integrated Management of the Sick Child. Bulletin of the World Health Organization 75 (Suppl 1), 7-24.

5. Aguilar A, Alvarado R, Cordero D, Kelly P, Zamora A \& Salgado R (1998) Mortality Survey in Bolivia, the Final Report: Investigating and Identifying the Causes of Death for Children Under Five. BASICS, Virginia.

6. Negussie Taffa and G. Chepngeno (2005). Determinants of health care seeking for childhood illnesses in Nairobi slums. Tropical Medicine and International Health. Volume 10 no 3 pp 240-245

7. Adegboyega AA, Onayade AA, Salawu O Careseeking behaviour of caregivers for common childhood illnesses in Lagos Island Local Government Area, Nigeria. Niger J Med. 2005 JanMar;14(1):65-71.

8. Mbonye AK, Prevalence of childhood illnesses and care-seeking practices in rural Uganda. Scientific World Journal. 2003 Aug 19;3:721-30

9. Tarimo DS, Lwihula GK, Minjas JN, Bygbjerg IC. Mothers' perceptions and knowledge on childhood malaria in the holendemic Kibaha district, Tanzania: implications for malaria control and the $\mid \mathrm{MCl}$ strategy. Trop Med Int Health. 2000 Mar;5(3):179-84.

10. Morbidity and Mortality Report. Ministry of Health, Dar es salaam, Tanzania; 1995
11. Zaman K, Zeitlyn S, Chakraborty J, de Francisco A \& Yunus M (1997) Acute lower respiratory infections in rural Bangladeshi children: patterns of treatment and identification of barriers. Southeast Asian Journal of Tropical Medicine and Public Health. 28, 99-106.

12. Hussain R, Lobo MA, Inam B, Khan A, Qureshi AF \& Marsh D (1997) Pneumonia perceptions and management: an ethnographic study in urban squatter settlements of Karachi, Pakistan. Social Science and Medicine. 45, 991-1004.

13. Reyes H, Tome P, Gutierrez G, Rodriguez R, Orozco M \& Guiscafre H (1998) Mortality for diarrheic disease in Mexico: problem of accessibility or quality of care? Salud Publica de Mexico. 40, 316-323.

14. Bojalil R (2002) Understanding Influences on the Quality of Care Given to Children by Private Doctors in Hidalgo, Mexico, PhDThesis. University of London, London. Www.coregroup.org/working_group/ imci_evidence_review.pdf

15. Baume C (2002) Comparing Care-seeking for Childhood Malaria: Lessons from Zambia and Kenya. BASICS, Virginia.

16. The Household and Community Component of $\mathrm{IMCl}$ : A Resource Manual on Strategies and Implementation Steps. Health Section, UNICEF, ESARO, July 1999, 4-6

17. Hill Z, Kirkwood B \& Edmond K (2001) Family and Community Practices that Promote Child Survival, Growth and Development: A Review of the Evidence. Paper commissioned by the Department of Child and Adolescent Health and Development, Family and Community Health, World Health Organization. Draft, September 2001. 